\title{
Amplitude of heat flow variations on Mars from possible shoreline topography
}

\author{
Javier Ruiz \\ Departamento de Geodinámica, Facultad de Ciencias Geológicas, Universidad Complutense de Madrid, Madrid, Spain \\ Received 15 March 2003; revised 2 September 2003; accepted 5 September 2003; published 20 November 2003. \\ [1] Analyses of the effective elastic thickness of the Martian lithosphere have been \\ previously used to calculate surface heat flow on Mars at different places and times. In this \\ work, I use elevation differences in a putative Late Hesperian shoreline, named \\ Deuteronilus shoreline, and the relation between thermal state and buoyancy of the \\ lithosphere, in order to estimate the amplitude of the variations of surface heat flow on \\ Mars, probably related to the time in which this feature was formed. The results suggest \\ that, if the Deuteronilus shoreline is a true paleo-equipotential surface, the relative \\ amplitude of surface heat flow variations on the shoreline regions in the Late Hesperian \\ were less than present-day ones in terrestrial continental areas. The results are also roughly \\ valid for the outer contact of the Late Hesperian Vastitas Borealis Formation, if this \\ contact is related to the limits of an ancient ocean. These results could imply that large \\ areas of the Martian lithosphere have been tectonothermally stable since at least that \\ time. INDEX TERMS: 1729 History of Geophysics: Planetology; 6225 Planetology: Solar System Objects: \\ Mars; 5418 Planetology: Solid Surface Planets: Heat flow; KEYWORDS: Mars, heat flow, deuteronilus \\ shorelines, Martian lithosphere
}

Citation: Ruiz, J., Amplitude of heat flow variations on Mars from possible shoreline topography, J. Geophys. Res., 108(E11), 5122, doi:10.1029/2003JE002084, 2003.

\section{Introduction}

[2] Previous works have proposed estimates of surface heat flows on Mars, deduced from the elastic and mechanical thickness of the lithosphere [e.g., Solomon and Head, 1990; Zuber et al., 2000; McGovern et al., 2002]. These works found differences between the heat flow deduced for different regions, but the interpretation of these regional differences needs to take into account that the heat flow for each region is proposed for the local loading time. In this manner, a decrease in heat flow through time is deduced for Mars [Zuber et al., 2000; McGovern et al., 2002], which is consistent with a decrease in internal heat sources through time. Also, it has been proposed [McGovern et al., 2002] that Hesperian and Amazonian volcanic areas in general show a higher heat flow than chasmata areas in the Valles Marineris region (Hesperian-Amazonian in age), which is consistent with the way those geological features formed.

[3] Besides these general results, this kind of methodology can hardly provide information about the amplitude of variations in lithosphere thermal state at a specific time, because the analyzed features cannot be strictly contemporaneous. The possible existence of an ocean on the northern lowlands in the late Hesperian [e.g., Parker et al., 1989, 1993; Clifford and Parker, 2001], however, could provide an paleo-equipotential surface (something subsequently distorted), which in turn could be used, in addition to the relation between surface elevation and thermal state of the

Copyright 2003 by the American Geophysical Union. 0148-0227/03/2003JE002084\$09.00 lithosphere [Lachenbruch and Morgan, 1990], to examine the amplitude of surface heat flow variations of large areas on Mars at a roughly concrete time in the Martian history. Indeed, if the lithosphere is hotter, the density is less and its thermal buoyancy is higher. This relation has been used to help constrain the thermal state of the lithosphere in continental areas of the Earth [Tejero and Ruiz, 2002]. This concept, although related, is not equal to the thermal isostasy due to oceanic lithosphere cooling [e.g., Turcotte and Schubert, 2002].

[4] Parker et al. [1989, 1993] proposed the existence in the northern lowlands of a contact (named Contact 2) marking the outer boundary of the northern plains, which was interpreted to be the shoreline of an ancient Martian ocean. This "contact" was later redrawn and renamed Deuteronilus shoreline by Clifford and Parker [2001]. Head et al. [1998, 1999] and Carr and Head [2003], using MOLA data, have shown that this putative shoreline represents a relatively good approximation to an equipotential surface. The proposed Deuteronilus shoreline has a mean altitude of $-3.792 \pm 0.236 \mathrm{~km}$, and its whole topographic range (Figure 1) is $\sim 1.1 \mathrm{~km}$, from -3.2 to $-4.3 \mathrm{~km}$ [Carr and Head, 2003]. Additionally, the elevation of the base levels of the Late Hesperian Chryse outflow channels, which are close to the mean level of Deuteronilus shoreline, in turn could indicate that they debouched into a large standing body of water [Head et al., 1999; Ivanov and Head, 2001]. However, specifically targeted MOC images have not found support for the shoreline hypothesis [Malin and Edgett, 1999, 2001], although these results have been disputed [Parker et al., 2001; Clifford and Parker, 2001; 


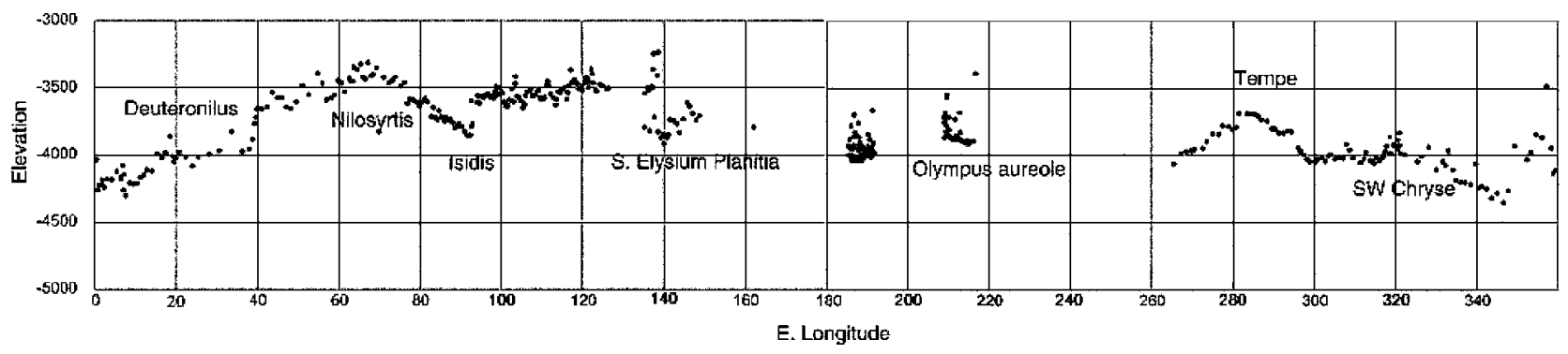

Figure 1. Elevations along Deuteronilus shoreline, adapted from Carr and Head [2003].

Fairén et al., 2003]. Similarly, from geologic and elevation relations of the Deuteronilus shoreline, an origin for this feature related to coastal processes is considered either unclear [Carr and Head, 2003] or likely [Webb and McGill, 2003].

[5] Otherwise, Carr and Head [2003] considered that the Late Hesperian Vastitas Borealis Formation, which extends for a great part of the northern lowlands, represents better support for the past existence of a large standing body of water on Mars. The Vastitas Borealis Formation has been interpreted as a sedimentary veneer at least $100 \mathrm{~m}$ thick on the East Hesperian ridged plains [Head et al., 2002], which could have originated as a sublimation residue from a large (probably frozen) water body [Kreslavsky and Head, 2002]. The outer contact of the Vastitas Borealis Formation is coincident with the trace of the Deuteronilus shoreline in the Deuteronilus, Nilosyrtis, Isidis, Tempe, and Chryse regions, but not in Elysium or the Olympus Mons aureole. If the outer contact of the Vastitas Borealis Formation in the Utopia basin is ignored (where it is covered by younger Amazonian Elysium materials, and therefore the original contact trace is not visible), the outer contact of the Vastitas Borealis Formation has a mean altitude of $-3.658 \pm 0.282 \mathrm{~km}$, with a whole topographic range of $\sim 1.0 \mathrm{~km}$, from -3.3 to $-4.3 \mathrm{~km}$ [Carr and Head, 2003, Figure 12].

[6] This paper is based on two assumptions. First: the Deuteronilus shoreline is a true paleo-equipotential surface, and then, present-day topographic variations in this feature postdate shoreline formation. Second: there were variations, currently greatly disappeared, in the thermal state of the lithosphere in regions along the Deuteronilus shoreline contemporaneously with the origin of this feature; the disappearance or attenuation of these variations (as is expected with the waning of internal heat sources) must result in the deformation of the original equipotential surface, since this was formed in equilibrium with the heat flow. Thus it is possible to calculate the amplitude of the ancient heat flow variations necessary to compensate present-day topography and transform the Deuteronilus shoreline into an equipotential surface. Like other geological processes could have produced vertical movements in the "Deuteronilus shoreline regions", the results obtained here suppose an upper limit to the amplitude of heat flow variations. The argument and results are also valid if the outer contact of the Vastitas Borealis Formation is considered to be an ancient oceanic limit (since the ranges of elevations are similar in both the Deuteronilus shoreline and the Vastitas Borealis Formation outer contact). Note that diverse processes, including geomorphologic evolution, can affect small-scale topographic variations; the rigidity of the
Martian lithosphere could also prevent small-scale isostatic adjustment. Therefore large wavelength topographic variations, in which isostatic adjustment can work, are more relevant for the purposes of this paper.

\section{Calculations}

[7] Because of thermal expansion and contraction, the elevation of the surface (referenced to the free heigh of the asthenosphere) depends on the thermal state of the lithosphere and has contributions from the lithospheric mantle and crust. (The term lithosphere is used here to define a thermally conductive layer, in which base isostatic compensation can be achieved.) The contribution due to the lithospheric mantle is

$$
H_{\mathrm{m}}=\alpha\left(\bar{T}_{\mathrm{m}}-T_{\mathrm{a}}\right) b_{\mathrm{m}},
$$

where $\alpha$ is the volumetric thermal expansion coefficient, $T_{\mathrm{a}}$ is the temperature of the asthenosphere, $\bar{T}_{\mathrm{m}}$ is the mean temperature of the lithospheric mantle, and $b_{\mathrm{m}}$ is the lithospheric mantle thickness; density differences between asthenospheric and lithospheric mantle are taken as solely due to temperature differences, which is a very reasonable approximation. A similar equation can be written to describe the crustal contribution, but taking into account a correction factor for the lesser crustal density:

$$
H_{\mathrm{c}}=\frac{\alpha \rho_{\mathrm{c}}}{\rho_{\mathrm{a}}}\left(\bar{T}_{\mathrm{c}}-T_{\mathrm{a}}\right) b_{\mathrm{c}},
$$

where $\rho_{\mathrm{c}}$ and $\rho_{\mathrm{a}}$ are respectively a reference crustal density and the density of the asthenosphere, and $b_{\mathrm{c}}$ is the crustal thickness.

[8] Here, I calculate $b_{\mathrm{m}}, \bar{T}_{\mathrm{m}}$, and $\bar{T}_{\mathrm{c}}$ in terms of the surface heat flow. I consider that there are heat sources homogeneously distributed in the crust. So, within the crust, the temperature at a depth $z$ is

$$
T_{\mathrm{z}}=T_{\mathrm{s}}+\frac{F z}{k_{\mathrm{c}}}\left(1-\frac{f z}{2 b_{\mathrm{c}}}\right)
$$

where $T_{\mathrm{s}}$ is the surface temperature, $F$ is the surface heat flow, $k_{\mathrm{c}}$ is the thermal conductivity of the crust, and $f$ is the fraction of the surface heat flow originated by radiogenic heating within the crust ( $f$ can be defined as $A b_{\mathrm{c}} / F$, where in turn, $A$ is the radioactive heating rate). I do not take into account the existence of heat sources in the lithospheric mantle (on Earth, radiogenic sources are sparse beneath the 


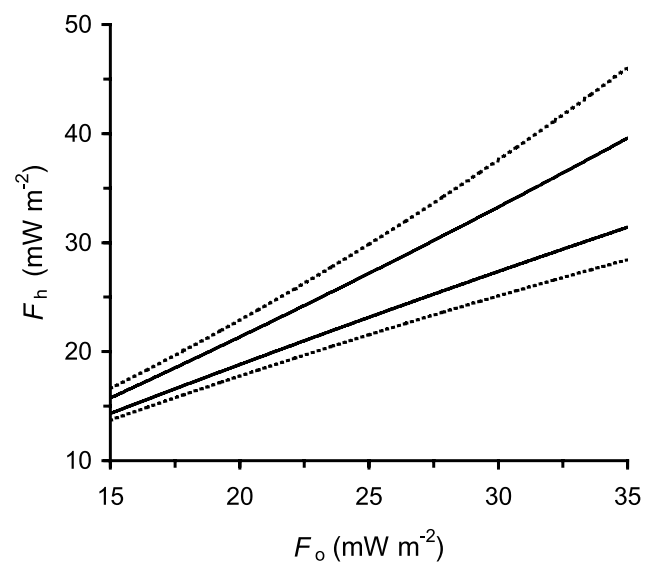

Figure 2. $F_{h}$ values for $h=550 \mathrm{~m}$ (lower curves) and $h=$ $-550 \mathrm{~m}$ (upper curves) in terms of $F_{\mathrm{o}}$. Dashed and solid lines indicate $f=0$ and $f=0.5$, respectively. In each case, the difference between the upper and lower curves gives the maximum surface heat flow variations permitted assuming the Deuteronilus shoreline as a paleo-equipotential surface.

near-surface radioactive element-rich layer, and within the lithospheric mantle, the heat flow can be assumed constant [e.g., Turcotte and Schubert, 2002]), and so, within the mantle lithosphere, the temperature at a depth $z$ is

$$
T_{\mathrm{z}}=T_{\mathrm{c}}+\frac{F(1-f)\left(z-b_{\mathrm{c}}\right)}{k_{\mathrm{m}}},
$$

where $T_{\mathrm{c}}$ is the temperature at the crust base, calculated taking $z=b_{\mathrm{c}}$ in equation (3); in turn, $b_{\mathrm{m}}$ is calculated from

$$
b_{\mathrm{m}}=b_{\mathrm{c}}+\frac{k_{\mathrm{m}}\left(T_{\mathrm{a}}-T_{\mathrm{c}}\right)}{F(1-f)} .
$$

Mean lithospheric mantle and crust temperatures are respectively given by

$$
\bar{T}_{\mathrm{m}}=\left(T_{\mathrm{a}}+T_{\mathrm{c}}\right) / 2,
$$

and

$$
\bar{T}_{\mathrm{c}}=\frac{1}{b_{\mathrm{c}}} \int_{0}^{b_{\mathrm{c}}} T(z) \mathrm{d} z .
$$

[9] The objective of this work is to analyze the amplitude of local variations in surface heat flow along the Deuteronilus shoreline necessary to make the present-day topography of this feature an equipotential surface. It can be performed by solving the equation

$$
-h=H_{\mathrm{m}}\left(F_{\mathrm{h}}\right)+H_{\mathrm{c}}\left(F_{\mathrm{h}}\right)-H_{\mathrm{m}}\left(F_{\mathrm{o}}\right)-H_{\mathrm{c}}\left(F_{\mathrm{o}}\right),
$$

where $h$ is the present-day local elevation with respect to a reference elevation (the sign minus refers to the fact that elevation differences must be compensated), $F_{h}$ is the local surface heat flow, and $F_{\mathrm{o}}$ is the heat flow for the reference elevation.

\section{Results}

[10] The calculations have been performed using $\alpha=3 \times$ $10^{-5}{ }^{\circ} \mathrm{C}^{-1}, k_{\mathrm{c}}=2.5 \mathrm{~W} \mathrm{~m}{ }^{-1}{ }^{\circ} \mathrm{C}^{-1}, k_{\mathrm{m}}=3.5 \mathrm{~W} \mathrm{~m}^{-1}{ }^{\circ} \mathrm{C}^{-1}$, $\rho_{\mathrm{c}}=2900 \mathrm{~kg} \mathrm{~m}^{-3}$, and $\rho_{\mathrm{a}}=3500 \mathrm{~kg} \mathrm{~m}^{-3}$. Higher crustal density or lower asthenospheric density reduces the variations in surface heat flow. The surface temperature is taken as $0^{\circ} \mathrm{C}$, maybe more appropriate for a time in which an ocean is assumed than the current mean surface temperature of about $-50^{\circ} \mathrm{C}$. The asthenospheric temperature is taken as $1300^{\circ} \mathrm{C}$, which is a typical value for the Earth's asthenosphere [e.g., Ranalli, 1997]. Crustal thickness is assumed to be a constant value of $40 \mathrm{~km}$, similar to the proposed by Zuber et al. [2000] for the crustal thickness below the northern lowlands from topography and gravity data. The degree of uncertainty in crustal thickness estimates is important. For example, from MGS data, diverse ranges of possible values for the mean crustal thickness have been proposed: $30-115 \mathrm{~km}$ [Nimmo and Stevenson, 2001], 80-100 km [Turcotte et al., 2002], $36-84 \mathrm{~km}$ [Wieczorek and Zuber, 2002], or 35-75 km [Nimmo, 2002]. However, if the crust is thicker, the relative variations in surface heat flow are lower, and so, for the purposes of this work, $40 \mathrm{~km}$ can be considered a useful value for the northern lowland crustal thickness.

[11] Two possibilities have been taken for the value of $f$, although I note that this value could locally vary: $f=0$ (corresponding to a linear thermal gradient through the crust) and $f=0.5$. The latter value is in accordance with the proposal (made from arguments drawn from the materials on Mars' surface) that perhaps over $50 \%$ (or even $75 \%$ ) of radioactive heat sources in this planet are placed in its crust [McLennan, 2001]; moreover, in the Earth, the 40$60 \%$ of the heat flow lost in continental areas originates from crustal heat sources [Pollack and Chapman, 1977; Turcotte and Schubert, 2002].

[12] In the calculations, $h$ is taken as $\pm 0.55 \mathrm{~km}$, for a total elevation range of $1.1 \mathrm{~km}$ (as discussed in the Introduction, the $h$ range used here puts an upper limit on the changes in relative elevation due to changes in the thermal state of the lithosphere, assuming the Deuteronilus shoreline is a true paleo-equipotential surface). This corresponds to a reference elevation (for which $h=0$ and $F_{\mathrm{h}}=F_{\mathrm{o}}$ ) of $-3.75 \mathrm{~km}$, close to the mean elevation of the Deuteronilus shoreline and to the mean elevation of the termini of the Chryse outflow channels. The $F_{\mathrm{o}}$ value is not known, and for that reason, the calculations have been performed for a range of $F_{\mathrm{o}}$

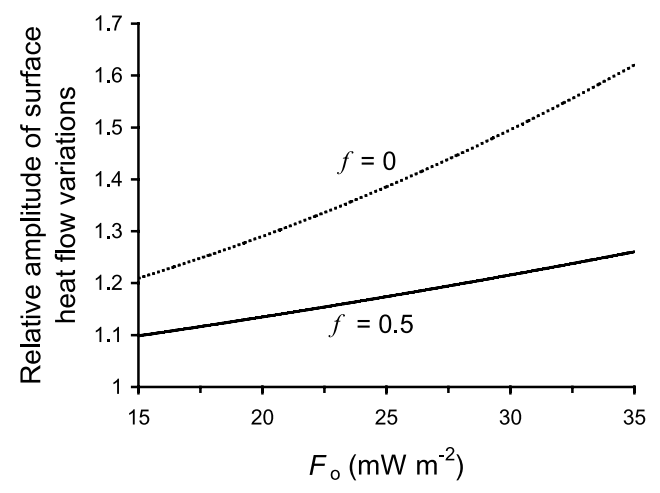

Figure 3. Upper limits to the relative amplitude of surface heat flow variations on the Deuteronilus shoreline (assumed to be a paleo-equipotential surface) locations. These relative amplitude upper limits are given by the ratio between upper and lower values shown in Figure 2. 
values between 15 and $35 \mathrm{~mW} \mathrm{~m}^{-2}$, a range based on estimates (uncertainty included) of the late Hesperian/early Amazonian elastic lithosphere thickness [Zuber et al., 2000; McGovern et al., 2002].

[13] Figure 2 shows $F_{h}$ values for $h= \pm 0.55 \mathrm{~km}$ in terms of $F_{\mathrm{o}}$. In each case, the difference between the upper and lower curves gives the maximum heat flow variations allowed, taking into account the Deuteronilus shoreline topography. Figure 3 shows upper limits to the relative amplitude of surface heat flow variations on Deuteronilus shoreline locations; these relative amplitude upper limits are the ratio between the maximum and minimum values shown in Figure 2.

\section{Discussion}

[14] It can be seen in Figures 2 and 3 that variations in heat flow in regions through the Deuteronilus shoreline were small in the Late Hesperian. In fact, the obtained upper limits for the relative amplitude of these variations are, at most, a factor of 1.6. If crustal heat sources are taken into account, the magnitude of the relative amplitude variations decreases for each given value of $F_{\mathrm{o}}$. For the $F_{\mathrm{o}}$ range used here, the depth to the $1300^{\circ} \mathrm{C}$ isotherm is $\sim 100-300 \mathrm{~km}$ for $f=0$ and $\sim 200-600 \mathrm{~km}$ for $f=0.5$. Since the small radius of Mars the calculations for the case $f=0.5$ (at low heat flows values) should take in account the spherical shape of Mars. In addition, the range of $F_{\mathrm{o}}$ values used here is based on works assuming linear thermal gradients [Zuber et al., 2000; McGovern et al., 2002]. Calculation of surface heat flows from elastic thicknesses would result in higher values if heat sources are present in the crust [Solomon and Head, 1990]. This, in turn, decreases the depth to the $1300^{\circ} \mathrm{C}$ isotherm and also increases the relative amplitude of variations in $F_{\mathrm{h}}$ for the case $f=0.5$. As the relative amplitude of $F_{\mathrm{h}}$ variations is clearly lower in the $f=0.5$ case than in the $f=0$ one, the main conclusions of this work are not altered.

[15] The upper limits for the relative amplitude of heat flow variations obtained here are clearly lower than those presently observed on Earth. On our planet, the higher heat flows are associated with seafloor spreading centers, but there is not clear evidence for plate tectonics at any moment of Mars's history (and, in any case, not for the late Hesperian or later on), and so, those heat flows are not relevant for this work. For instance, contoured maps of terrestrial heat flow show variations in continental areas that can be higher than a factor 2 or 3 [e.g., Pollack et al., 1993; Cermak, 1993]. Those areas include terrains of different ages, and it is known for continental areas that an inverse relation exists between surface heat flow and age of the last tectonothermal stabilization [e.g., Hamza, 1979; Vitorello and Pollack, 1980; Cermak, 1993].

[16] As indicated in the introduction, if surface heat flow variations on Mars are currently almost disappeared, then the upper limits to the heat flows variations deduced of Deuteronilus shoreline topography are related to the time when this feature was formed (i.e., the Late Hesperian, 3 Gyr ago [Hartmann and Neukum, 2001]). In this case, the present-day elevation range along Deuteronilus shoreline suggests that differences in the thermal state of the lithosphere in the "Deuteronilus shoreline regions" have been relatively small since the feature was formed, and therefore that very large areas of the Martian lithosphere has been tectonothermally stable since the Late Hesperian. This is consistent with near complete building of the Tharsis rise by the end of the Noachian [Phillips et al., 2001], with a significant decrease in volcanic resurfacing rates following the Hesperian's end [e.g., Hartmann and Neukum, 2001] and with the localization of the waning Amazonian magmatic and tectonic activity at areas in Tharsis and Elysium [e.g., Anderson et al., 2001; Dohm et al., 2001; Head et al., 2001].

[17] Alternatively, reheating of the lithosphere postdating the Deuteronilus shoreline could have caused, or contributed to, the distortion of the topography. In this case, the reheating should have been maintained (at least partially) until the present time, since the dissipation of the thermal anomalies should lead to the disappearance of their effect on the topography. However, as above mentioned, Amazonian geological activity represents the waning and localized magmatic and tectonic activity on Mars, and for that reason, the upper limits to the heat flow variations obtained in this work more probably refer to the thermal state of the Martian lithosphere when the Deuteronilus shoreline was formed.

\section{Conclusions}

[18] If the Deuteronilus shoreline (or equivalently, the outer contact of the Vastitas Borealis Formation) represents a Late Hesperian paleo-equipotential surface, then three conclusions can be deduced from this work. First, the relative variations in Late Hesperian surface heat flow in shoreline regions were lower than relative variations in present-day surface heat flow in continental areas on Earth. Second, if substantial amounts of radiogenic heat sources are located in the Martian crust, these relative variations are likely lower. Finally, very large areas of the Martian lithosphere has been tectonothermally stable since (at least) the Late Hesperian.

[19] Acknowledgments. The author thanks Alberto G. Fairén, Andrew J. Dombard, and Angélica Torices for productive comments and help with the manuscript, and Patrick McGovern and an anonymous referee for critical reviews, which greatly improved this paper. This work was supported by a grant from the Spanish Secretaría de Estado de Educación y Universidades.

\section{References}

Anderson, R. C., J. M. Dohm, M. P. Golombek, A. F. C. Haldemann, B. J. Franklin, K. L. Tanaka, J. Lias, and B. Peer, Primary centers and secondary concentrations of tectonic activity through time in western hemisphere of Mars, J. Geophys. Res., 106, 20,563-20,585, 2001.

Carr, M. H., and J. W. Head, Oceans on Mars: An assessment of the observational evidence and possible fate, J. Geophys. Res., 108(E5), 5042, 10.1029/2002JE001963. 2003.

Cermak, V., Lithospheric thermal regimes in Europe, Phys. Earth Planet. Inter., 79, 179-193, 1993.

Clifford, S. M., and T. J. Parker, The evolution of the Martian hydrosphere: Implications for the fate of a primordial ocean and the current state of the Northern Plains, Icarus, 154, 40-79, 2001.

Dohm, J. M., J. C. Ferris, V. R. Baker, R. C. Anderson, T. M. Hare, R. G. Strom, N. G. Barlow, K. L. Tanaka, J. E. Klemaszewski, and D. H. Scott, Ancient drainage basin of the Tharsis region, Mars: Potential source for outflow channel systems and putative oceans or paleolakes, J. Geophys. Res., 106, 32,943-32,958, 2001

Fairén, A. G., J. M. Dohm, V. R. Baker, M. A. de Pablo, J. Ruiz, J. C. Ferris, and R. C. Anderson, Episodic flood inundations of the northern plains of Mars, Icarus, 165, 53-67, 2003.

Hamza, V. M., Variation of continental mantle heat flow with age: Possibility of discriminating between thermal models of the lithosphere, Pure Appl. Geophys., 117, 65-74, 1979. 
Hartmann, W. K., and G. Neukum, Cratering chronology and the evolution of Mars, Space Sci. Rev., 96, 165-194, 2001.

Head, J. W., M. Kreslavsky, H. Hiesinger, M. A. Ivanov, S. Pratt, N. Seibert, D. E. Smith, and M. T. Zuber, Oceans in the past history of Mars: Test for their presence using Mars Orbiter Laser Altimeter (MOLA) data, Geophys. Res. Lett., 25, 4401-4404, 1998.

Head, J. W., H. Hiesinger, M. A. Ivanov, M. A. Kreslavsky, S. Pratt, and B. J. Thomson, Possible ancient oceans on Mars: Evidence from Mars Orbiter Laser Altimeter data, Science, 286, 2134-2137, 1999.

Head, J. W., R. Greeley, M. P. Golombek, W. K. Hartmann, E. Hauer, R. Jaumann, P. Masson, G. Neukum, L. E. Nyquist, and M. H. Carr, Geological processes and evolution, Space Sci. Rev., 96, 263-292, 2001.

Head, J. W., III, M. A. Kreslavsky, and S. Pratt, Northern lowlands of Mars: Evidence for widespread volcanic flooding and tectonic deformation in the Hesperian Period, J. Geophys. Res., 107(E1), 5003, 10.1029/ 2000JE001445, 2002

Ivanov, M. A., and J. W. Head, Chryse Planitia, Mars: Topographic configuration, outflow channel continuity and sequence, and test for hypothesized ancient bodies of water using Mars Orbiter Laser Altimeter (MOLA) data, J. Geophys. Res., 106, 3275-3295, 2001.

Kreslavsky, M. A., and J. W. Head, Fate of outflow channel effluents in the northern lowlands of Mars: The Vastitas Borealis Formation as a sublimation residue from frozen ponded bodies of water, J. Geophys. Res., 107(E12), 5121, 10.1029/2001JE001831, 2002

Lachenbruch, A. H., and P. Morgan, Continental extension, magmatism and elevation; formal relations and rules of thumb, Tectonophysics, 174, 3962, 1990.

Malin, M. C., and K. C. Edgett, Oceans or seas in the martian northern lowlands: High resolution imaging test of proposed coastlines, Geophys. Res. Lett., 26, 3049-3052, 1999.

Malin, M. C., and K. C. Edgett, Mars Global Surveyor Mars Orbiter Camera Interplanetary cruise through primary mission, J. Geophys. Res., 106, $23,429-23,570,2001$.

McGovern, P. J., S. C. Solomon, D. E. Smith, M. T. Zuber, M. Simons, M. A. Wieczorek, R. J. Phillips, G. A. Neumann, O. Aharonson, and J. W. Head, Localized gravity/topography admittance and correlation spectra on Mars: Implications for regional and global evolution, J. Geophys. Res., 107(E12), 5136, 10.1029/2002JE001854, 2002.

McLennan, S. M., Crustal heat production and the thermal evolution of Mars, Geophys. Res. Lett., 28, 4019-4022, 2001.

Nimmo, F., Admittance estimates of mean crustal thickness and density at the Martian hemispheric dichotomy, J. Geophys. Res., 107(E11), 5117, 10.1029/2000JE001488, 2002.

Nimmo, F., and D. J. Stevenson, Estimates of Martian crustal thickness from viscous relaxation of topography, J. Geophys. Res., 106, 50855098,2001
Parker, T. J., R. S. Saunder, and D. M. Schneeberger, Transitional morphology in west Deuteronilus Mensae, Mars: Implications for modification of the lowland/upland boundary, Icarus, 82, 111-145, 1989.

Parker, T. J., D. S. Gorsline, R. S. Saunders, D. C. Pieri, and D. M. Schneeberger, Coastal geomorphology of the Martian northern plains, J. Geophys. Res., 98, 11,061-11,078, 1993.

Parker, T. J., J. A. Grant, B. J. Franklin, and J. W. Rice, A comparison of MOC and MOLA observations of northern plains "contacts" with coastal landforms of the Bonneville basin [CD-ROM], Utah, Lunar Planet. Sci., 32, 2001.

Phillips, R. J., et al., Ancient geodynamics and global-scale hydrology on Mars, Science, 291, 2587-2591, 2001.

Pollack, H. N., and D. S. Chapman, Mantle heat flow provinces, Earth Planet. Sci. Lett., 34, 174-184, 1977.

Pollack, H. N., S. J. Hunter, and J. R. Johnson, Heat flow from the Earth interior: Analysis of the global data set, Rev. Geophys., 31, 267-280, 1993.

Ranalli, G., Rheology of the lithosphere in space and time, in Orogeny Through Time, edited by J. P. Burg and M. Ford, Geol. Soc. Spec. Publ., 121, 19-37, 1997.

Solomon, S. C., and J. W. Head, Heterogeneities in the thickness of the elastic lithosphere of Mars: Constraints on heat flow and internal dynamics, J. Geophys. Res., 95, 11,073-11,083, 1990.

Tejero, R., and J. Ruiz, Thermal and mechanical structure of the central Iberian Peninsula lithosphere, Tectonophysics, 350, 49-62, 2002.

Turcotte, D. L., and G. Schubert, Geodynamics, 2nd ed., 456 pp., Cambridge Univ. Press, New York, 2002.

Turcotte, D. L., R. Shcherbakov, B. D. Malamud, and A. B Kucinskas, Is the Martian crust also the Martian elastic lithosphere?, J. Geophys. Res., 107(11), 5091, 10.1029/2001JE001594, 2002.

Vitorello, I., and H. N. Pollack, On the variation of continental heat flow with age and thermal evolution of the continents, J. Geophys. Res., 85, $983-995,1980$

Webb, V. E., and G. E. McGill, Assessing the geomorphic development of putative shorelines contiguous to Northern Arabia Terra, Mars [CD-ROM], Lunar Planet. Sci., 34, 2003.

Wieczorek, M. A., and M. T. Zuber, The thickness of the Martian crust as inferred from geoid-to-topography ratios [CD-ROM], Lunar Planet. Sci., 33, 2002.

Zuber, M. T., et al., Internal structure and early thermal evolution of Mars from Mars Global Surveyor, Science, 287, 1788-1793, 2000.

J. Ruiz, Departamento de Geodinámica, Facultad de Ciencias Geológicas, Universidad Complutense de Madrid, 28040 Madrid, Spain. (jaruiz@ geo.ucm.es) 